\title{
ВЫПУСК ОБЛИГАЦИЙ МЕСТНЫХ ОРГАНОВ ВЛАСТИ - РЕШЕНИЕ ПО РЕАЛИЗАЦИИ СТРАТЕГИИ ГОСУДАРСТВЕННОГО ДОЛГА ВЬЕТНАМА
}

\author{
Дао Тхань Бинь, \\ binh.daothanh@hust.edu.vn \\ Ханойский университет науки и технологий, \\ Вьетнам, 11615, Ханой, ул. Дай Ко Вьет, 1
}

Дао Тхань Бинь, PhD, заведующий кафедрой финансового менеджмента Школы экономики и менеджмента, Ханойский университет науки и технологий.

Несмотря на сложную международную обстановку, обостренную геополитической напряженностью в мире и пандемией COVID-19, экономика Вьетнама постепенно восстанавливается, однако определенные трудности и проблемы остаются до сих пор. В последние годы благодаря активной работе Правительства Социалистической Республики Вьетнам, своевременным решениям Министерства финансов, других профильных ведомств и учреждений, а также местных органов власти были поэтапно реализованы цели Стратегии государственного долга, соответствующие реализации задач социально-экономического развития, сокращения уровня бедности и асинхронного создания необходимой инфраструктуры. К 2020 2. показатели госдолга Социалистической Республики Вьетнам в основном находятся в пределах допустимых границ, но с точки зрения обязательств по выплате долга в ближайшее время потенциальные риски все еще остаются. Статья посвящена оценке результатов реализации Стратегии государственного долга Вьетнама на 2011-2020 г2. с целью предоставления соответствующих рекомендаций по обеспечению национальной финансовой безопасности, а также мобилизации ресурсов облигаций местных органов власти для эффективного и устойчивого экономического роста и развития.

Ключевые слова: Государственный бюджет, государственный долг, Стратегия государственного долга Вьетнама, облигации местных органов власти.

\section{Итоги реализации Стратегии государственного долга до 2020 г.}

В 2011-2016 гг. Правительство Социалистической Республики Вьетнам (СРВ) определило источники капитала, направленные на обеспечение сбалансированности государственного бюджета, и продолжало финансировать программы и проекты по строительству транспортной инфраструктуры, ирригационных систем, медицинских и образовательных учреждений. Кроме того, была продолжена работа по ключевым целевым программам в соответствии с постановлениями Национального собрания СРВ [1].

В частности, за 2011-2016 гг. сумма займов для компенсации дефицита государственного бюджета составила более 1200 трлн донгов (почти $6 \%$ от ВВП). Средства предназначены для финансирования программ и инвестиционных проектов в области транспортной инфраструктуры, социальных объектов и других отраслей, которые не могут напрямую вернуть капитал в рамках расходной части государственного бюджета. Если разбить общую сумму займа (1200 трлн донгов) на составляющие, то выходит следующая картина:

- государственный внутренний заем составил более 800 трлн донгов (около 70 \% от общей суммы);

- заем по линии ОПР - почти 400 трлн донгов. 
Кроме того, стоит отметить увеличение числа государственных облигаций (ГО) в 1,9 раза в сравнении с 2006-2010 гг. ГО предназначены для дальнейшего укрепления инвестиционных вложений в социально-экономическое развитие. Так, объем инвестиционных вложений в транспортную инфраструктуру составил более $50 \%$, в ирригационные системы - более $20 \%$, в медицинские объекты - более $10 \%$, в образование и профессиональную подготовку - почти $2 \%$, а взаимный капитал по линии ОПР составил более $5 \%$.

Правительство СРВ также аккумулирует часть иностранного капитала на повторное кредитование на сумму более 250 трлн донгов. Средства предназначены для инвестиций в такие секторы и отрасли, как электроэнергетика, нефть и газ, авиация и скоростные автомагистрали, морские порты, водоснабжение, переработка сельхозпродукции, промышленное производство и развитие городской инфраструктуры. Это в свою очередь способствует сокращению прямых обязательств правительства по погашению задолженности по долгу из госбюджета.

Таблища 1. Обобщение ситуащии с государственным долгом за 2011-2016 г2. [3] Table 1. Generalization of the situation with public debt for 2011-2016 [3]

\begin{tabular}{|c|c|c|c|c|c|c|}
\hline Наименование показателя/Indicator name & 2011 & 2012 & 2013 & 2014 & 2015 & 2016 \\
\hline $\begin{array}{l}\text { Государственный долг, трлн донгов } \\
\text { State debt, trillion dongs }\end{array}$ & 1,391 & 1,647 & 1,953 & 2,284 & 2,608 & 3,004 \\
\hline $\begin{array}{l}\text { Долговые обязательства правительства, трлн донгов } \\
\text { Government debt, trillion dongs }\end{array}$ & 1,093 & 1,279 & 1,528 & 1,826 & 2,108 & 2,462 \\
\hline $\begin{array}{l}\text { Внутренний долг, трлн донгов } \\
\text { Domestic debt, trillion dongs }\end{array}$ & 425 & 552 & 765 & 1,016 & 1,201 & 1,441 \\
\hline $\begin{array}{l}\text { Внешний долг, трлн донгов } \\
\text { External debt, trillion dongs }\end{array}$ & 667 & 727 & 763 & 810 & 907 & 1,022 \\
\hline $\begin{array}{l}\text { Гарантированный правительством долг, трлн донгов } \\
\text { Government-guaranteed debt, trillion dongs }\end{array}$ & 287 & 343 & 396 & 423 & 464 & 497 \\
\hline $\begin{array}{l}\text { Внутренний, трлн донгов } \\
\text { Interior, trillion dongs }\end{array}$ & 171 & 192 & 208 & 212 & 206 & 214 \\
\hline $\begin{array}{l}\text { Банк развития Вьетнама, трлн донгов } \\
\text { Vietnam Development Bank, trillion dongs }\end{array}$ & 116 & 127 & 139 & 142 & 128 & 132 \\
\hline $\begin{array}{l}\text { Банк социальной политики, трлн донгов } \\
\text { Bank for Social Policy, trillion dongs }\end{array}$ & 18 & 28 & 29 & 29 & 34 & 38 \\
\hline $\begin{array}{l}\text { Гарантии предприятия, трлн донгов } \\
\text { Enterprise guarantees, trillion dongs }\end{array}$ & 37 & 38 & 39 & 41 & 44 & ? \\
\hline $\begin{array}{l}\text { Внешний трлн донгов } \\
\text { External, trillion dongs }\end{array}$ & 117 & 151 & 188 & 211 & 258 & 282 \\
\hline $\begin{array}{l}\text { Долг местных органов власти, трлн донгов } \\
\text { Local government debt, trillion dongs }\end{array}$ & 11 & 25 & 28 & 35 & 36 & 45 \\
\hline $\begin{array}{l}\text { Государственный внешний долг, трлн донгов } \\
\text { Public external debt, trillion dongs }\end{array}$ & 1,054 & 1,214 & 1,336 & 1,509 & 1,808 & 2,083 \\
\hline \multicolumn{7}{|l|}{$\begin{array}{l}\text { Показатель долга к ВBП, \% } \\
\text { Debt to GDP Ratio, \% }\end{array}$} \\
\hline $\begin{array}{l}\text { Государственный долг/ВВП, \% } \\
\text { Government debt/GDP, \% }\end{array}$ & 50,0 & 50,0 & 54,50 & 58,0 & 62,2 & 63,7 \\
\hline $\begin{array}{l}\text { Долговые обязательства правительства/ВВП, \% } \\
\text { Government debt/GDP, \% }\end{array}$ & 39,3 & 39,4 & 42,6 & 46,4 & 50,3 & 52,7 \\
\hline $\begin{array}{l}\text { Гарантированный правительством долг/ВВП, \% } \\
\text { Government Guaranteed Debt/GDP, \% }\end{array}$ & 10,3 & 10,6 & 11,1 & 10,7 & 10,7 & 10,8 \\
\hline $\begin{array}{l}\text { Долг местных органов власти (MOB)/BВП, \% } \\
\text { Local Government Debt /GDP, \% }\end{array}$ & 0,4 & 0,8 & 0,8 & 0,9 & 0,9 & 1,0 \\
\hline
\end{tabular}


За 2011-2016 гг. провинциальные и муниципальные органы власти привлекли более 120 трлн донгов в виде кредитов на развитие местной инфраструктуры и на реализацию проектов и объектов, утвержденных в планах по социально-экономическому развитию регионов. Результаты реализации Стратегии государственного долга за 2011-2016 гг. представлены в табл. 1.

На ранних этапах реализации Стратегии госдолга увеличение объема мобилизации внутреннего капитала привело к использованию краткосрочных кредитов на долгосрочные инвестиции, что создает риски рефинансирования и затрудняет погашение займа в короткий срок. В связи с этим в конце 2014 г. в Стратегию были внесены изменения, в результате чего срок выпуска ГО был увеличен до 4,8 лет, что соответствует целевому показателю на 2011-2015 гг. в 4-6 лет. Это решение способствовало минимизации риска рефинансирования и ликвидности портфеля долговых обязательств со стороны Правительства СРВ.

Выплата долговых обязательств правительства включает в себя прямое погашение долговых обязательств государства, а также выплату в счет погашения долга при перекредитовании в целях недопущения образования просроченной задолженности, влияющей на национальный кредитный рейтинг. Коэффициент прямого погашения долговых обязательств правительства в 2011-2016 гг. составил в среднем более 14 \% от общих доходов государственного бюджета (ГБ) (при установленном лимите не более $25 \%$ ) [1]. Кроме того, в более стабильных макроэкономических условиях новая часть кредитов с долгосрочными и более низкими процентными ставками также будет использоваться для реструктуризации просроченной задолженности, снижения стоимости кредитов, уменьшения давления на погашение долга государственного бюджета в краткосрочной перспективе.

Показатели долга Вьетнама находятся в пределах границ, установленных Стратегией госдолга. По состоянию на конец 2016 г. государственный долг составил более $60 \%$ от ВВП, долговые обязательства правительства - более $50 \%$, а внешний долг страны более $40 \%$. Если говорить о структуре государственного долга, то на конец 2016 г. на долговые обязательства правительства приходилось более 80 \% непогашенных кредитов, на гарантированный правительством долг - около 18 \%, а также на долг местных органов власти (долг МОВ) - почти $2 \%$. В структуре долговых обязательств правительства доля внутреннего долга изменилась на 20 \% (с почти 40 \% в 2011 г. до 60 \% в 2016 г.), а внешнего долга соответственно с более $60 \%$ до более 40 \% к 2016 г. Доля займов по линии ОПР и льготного кредитования в структуре внешнего долга правительства осталась на высоком уровне, превышающем 90 \%, что способствует минимизации валютного риска, сбалансированному риску рефинансирования портфеля внешнего долга и обеспечению национальной финансовой безопасности.

Таким образом, за 2011-2016 гг. коэффициент отношения государственного долга к ВВП Вьетнама все еще остается высоким, а займы в структуре ОПР по-прежнему составляют значительную долю, создавая риски к своевременному погашению долга и образованию дефицита в ГБ, поскольку процентные расходы в ближайшие годы будут продолжать расти. В связи с этим Стратегия государственного долга на 2017-2020 гг. и ее видение до 2030 г. были частично изменены в целях удовлетворения потребностей правительства в капитале с низкими затратами, связанными с разумным уровнем рисков, способностью погашать долги, развития внутреннего рынка капитала, поэтапной реструктуризации государственного долга и национальной финансовой безопасности. Стратегия государственного долга на 2017-2020 гг. будет реализована со следующими критериями: 
- государственный долг не должен превышать 65 \% от ВВП (на прямые долговые обязательства должно приходиться не более 54 \% ВВП);

- обязательства Правительства СРВ по прямому погашению долга по сравнению с общими годовыми доходами ГБ не должны быть выше $25 \%$;

- средний срок выпуска государственных облигаций составит 6-8 лет;

- ежегодное обязательство страны по погашению внешнего долга составляет менее $25 \%$ от стоимости экспорта товаров и услуг;

- государственный валютный резерв - более $200 \%$ от общего годового сальдо краткосрочного внешнего долга;

- объем внешнего долга правительства - менее 45 \% от общего объема долговых обязательств правительства [2].

На перспективу до 2030 г. государственный долг не должен превышать 60 \% от ВВП, из которых на объем долговых обязательств придется не более 50 \% ВВП, а государственный внешний долг не может превысить 45 \% ВВП [1].

Для реализации данной стратегии необходимо не только сократить долю внешнего долга, но и постепенно увеличивать внутренний мобилизованный капитал за счет облигаций государства и местных органов власти (OMOB). Некоторые показатели, отражающие результаты реализации Стратегии государственного долга на 2017-2020 гг., представлены в табл. 2.

Таблица 2. Целевые показатели реализации Стратегии государственного долга за 2017-2020 г2. [4]

Table 2. Target indicators for implementation of the Public Debt Strategy for 2017-2020 [4]

\begin{tabular}{|c|c|c|c|c|c|c|c|}
\hline $\begin{array}{c}\text { Наименование показателя } \\
\text { Indicator name }\end{array}$ & $\begin{array}{c}\text { Годовая } \\
\text { цель } \\
\text { Annual } \\
\text { target }\end{array}$ & 2017 & 2018 & 2019 & $\begin{array}{c}2020 \\
\text { (оценочная) } \\
2020 \\
\text { (estimated) } \\
\end{array}$ & $\begin{array}{l}\text { Результат } \\
\text { Result }\end{array}$ & $\begin{array}{l}\text { Прогноз } \\
\text { на } 2021 \text { г. } \\
\text { Forecast } \\
\text { for } 2021\end{array}$ \\
\hline $\begin{array}{l}\text { Государственный долг/ВВП, \% } \\
\text { Government debt/GDP, \% }\end{array}$ & $\leq 65$ & 61,4 & 58,3 & 55,0 & 56,8 & $\begin{array}{c}\text { Успешно } \\
\text { Successfully }\end{array}$ & 46,1 \\
\hline $\begin{array}{l}\text { Долговые обязательства } \\
\text { правительства/ВBП, \% } \\
\text { Government debt/GDP, \% }\end{array}$ & $\leq 54$ & 51,7 & 49,9 & 48,0 & 50,8 & $\begin{array}{l}\text { Успешно } \\
\text { Successfully }\end{array}$ & 41,9 \\
\hline $\begin{array}{l}\text { Государственный внешний } \\
\text { долг/BBП, \% } \\
\text { Public external debt/GDP, \% }\end{array}$ & $\leq 50$ & 49,0 & 46,0 & 47,1 & 47,9 & $\begin{array}{l}\text { Успешно } \\
\text { Successfully }\end{array}$ & - \\
\hline $\begin{array}{l}\text { Обязательство по погашению } \\
\text { государственного внешнего } \\
\text { долга/экспорт товаров услуг, \% } \\
\text { Obligation to repay public external } \\
\text { debt/Export of goods, services, \% }\end{array}$ & $<25$ & 36,1 & 37,5 & 30,7 & 34,6 & $\begin{array}{l}\text { Неуспешно } \\
\text { Unsuccessfully }\end{array}$ & - \\
\hline $\begin{array}{l}\text { Обязательства правительства } \\
\text { по прямому погашению долга/ } \\
\text { доход ГБ, \% } \\
\text { Government commitments } \\
\text { for direct debt repayment/ } \\
\text { State budget revenue, \% }\end{array}$ & $\leq 25$ & 19,7 & 16,1 & 17,4 & 24,1 & $\begin{array}{l}\text { Успешно } \\
\text { Successfully }\end{array}$ & 27,4 \\
\hline $\begin{array}{l}\text { Средний срок выпуска } \\
\text { государственных облигаций, лет } \\
\text { Average maturity of government } \\
\text { bonds (per year) }\end{array}$ & $6-8$ & 12,7 & 12,7 & 13,4 & $13-13,5$ & $\begin{array}{l}\text { Успешно } \\
\text { Successfully }\end{array}$ & - \\
\hline
\end{tabular}


В рассматриваемый период средний экономический рост составил 6,5 \% в год, инфляция - менее 5 \% в год, дефицит ГБ по состоянию на конец 2020 г. составил около 4 $\%$ ВВП. Займы по линии ОПР, иностранные льготные госкредиты и займы под гарантии правительства по-прежнему производятся в соответствии с действующими нормативными актами, а кредиты МОВ постепенно увеличиваются (в основном за счет выпуска облигаций местных органов власти) в соответствии с положениями закона о ГБ на 2015 г. В частности, соотношение долга МОВ к ВВП значительно увеличилось с более чем 1 \% в 2011-2016 гг. до более $2 \%$ к 2020 г. [2]. Привлечение кредитных средств позволило MOB мобилизовать внутренний капитал на инвестиции в инфраструктуру в соответствии со стратегией роста экономики каждого отдельного населенного пункта, а также снизить нагрузку на Центральный банк. В результате и источник капитала ОМОВ был расширен, что способствовало реализации закона о ГБ на 2015 г.

Тем не менее реализация Стратегии государственного долга в вышеуказанный период по-прежнему осуществлялась с большим трудом из-за ряда проблем:

- в условиях неразвитого внутреннего рынка мобилизация необходимого объема капитала будет трудно осуществимой;

- разница между обязательствами Правительства СРВ по погашению долгов и доходами ГБ превысит установленный лимит (разница в некоторые годы может достигать почти $30 \%$ );

- целевые показатели государственного сектора по сравнению с ВВП уже превысили лимит, установленный в Национальной стратегии государственного и государственного внешнего долга на 2011-2020 гг. и на перспективу до 2030 г. - 70 \% долговых обязательств правительства или почти 50 \% ВВП [2].

Исходя из вышеупомянутых фактов, поддержание коэффициента дефицита государственного бюджета и лимита по предоставлению госгарантии в соответствии с текущим планом приведет к тому, что целевой показатель государственного долга к ВВП превысит установленный лимит за весь период. В целях обеспечения безопасности государственного долга и национальной финансовой безопасности кредитные обязательства правительства к ВВП должны находиться в допустимых пределах. Для этого необходимо принять меры по корректировке планов получения заемных средств и погашения кредитов и долгов, а именно сократить перерасход средств в соответствии с законом о ГБ на 2015 г. в среднем до 3,6 \% ВВП, снизить банковские гарантии двух национальных банков - VDB (Vietnam Development Bank) и VBSP (Vietnam Bank for Social Policies), a также их политику в отношении новой эмиссии обязательством по погашению годового долга. Это необходимо для обеспечения стабильной и прогнозируемой ситуации по задолженности в будущем. Кроме того, следует приостановить все новые эмиссии с гарантиями правительства по внутренним и внешним займам.

Для мобилизации капитала необходимо сократить дефицит ГБ и гарантии правительства, выполнить мобилизацию капитала правительством в 2017-2020 гг. в направлении сокращения займов по линии ОПР и внешних источников льготного капитала при одновременном увеличении внутренних заимствований - от выпуска ГО и до увеличения выпуска OMOB.

Структура источников мобилизации капитала построена на основе приоритетного направления на снижение курсового риска портфеля долговых обязательств правительства с учетом возможности постепенного уменьшения капитала по линии ОПР и иностранных льготных кредитов. Взамен необходимо сосредоточиться на мобилизации внутренних ресурсов для удовлетворения потребностей правительства в заемных средствах (около $75 \%$ за счет внутренних займов, а $25 \%$ за счет внешних). В то же время 
такая структура мобилизации капитала обеспечивает соблюдение Постановлений Национального собрания № 73/2013/QH13 и № 99/2015/QH13 о сокращении пролонгации долга, продлении срока погашения портфеля долга и снижении рисков рефинансирования капитала.

\section{Риск превышения верхнего порога государственного долга и потребность в выпуске облигаций местных органов власти}

Стратегия государственного долга и внешнего долга на 2011-2020 гг. и на перспективу до 2030 г. устанавливает верхних порог госдолга в СРВ не более 65 \% ВВП, из которых долговые обязательства правительства составляют не более 55 \% ВВП, а государственный внешний долг - не может превышать 50 \% ВВП. Для сравнения возьмем верхний порог долга в странах с эквивалентным Вьетнаму кредитным рейтингом: в Филиппинах он составляет 57,5 \% ВВП, Уругвае - 69 \% ВВП, Турции - 47,6 \% ВВП, Египте 73,8 \% ВВП, Латвии - 48,6 \% ВВП. Данные пороги необходимы для безопасного и устойчивого контроля над государственным долгом. Однако в случае, если экономический рост или номинальное значение ВВП в ближайшие годы окажутся ниже ожидаемого, то отношение долга к ВВП превысит допустимый предел. Более того, если темпы роста ВВП в 2020-2025 гг. составят лишь 5,9-6,0 \% в год, а годовой объем привлеченных кредитных средств не будет уменьшаться, то отношение долговых обязательств к ВВП достигнет значений в 68-70 \% ВВП. В случае, если фактический дефицит ГБ или реализация дорожной карты по сокращению дефицита не будет соответствовать ожиданиям, то отношение долга к ВВП и целевой показатель погашения прямого долга правительства по сравнению с годовыми доходами ГБ превысят установленный предел.

Привлечение средств через ОПР и льготные кредиты сверх предельного уровня, предусмотренного в среднесрочном плане государственных инвестиций, относится к расходной части государственного бюджета, что ведет к его перерасходу, увеличению государственного долга и обязательств Правительства СРВ по погашению прямой задолженности. Возникновение условных обязательств может превратиться в государственный долг в процессе реструктуризации экономики, государственных инвестиций и предприятий, а также системы коммерческих банков и кредитных организаций. Более того, изменения процентных ставок или обменного курса валют будут оказывать влияние на размеры непогашенной задолженности и кредитных обязательств при расчете в донгах (национальной валюте СРВ).

Учитывая высокий коэффициент долга Правительства СРВ и низкую кредитную нагрузку МOB, настало время для децентрализации бюджета, по крайней мере в отношении провинций. Правительству следует постепенно сокращать ежегодную субсидию от центрального бюджета, предоставив местным органам власти автономию в вопросах мобилизации инвестиционного капитала, в том числе дать им право выпускать ОМОВ.

Закон о ГБ № 83 / 2015 / QН13 позволяет с 2017 г. муниципальным бюджетам допускать перерасход средств, если в этом есть необходимость для осуществления проектов и работ в рамках инвестиционного капитала. Не допустить дефицит в бюджетах провинций и муниципалитетов можно за счет выпуска облигаций МОВ.

Мы понимаем, что наиболее лучший и оптимальный вариант - это удерживать баланс между расходной и доходной частями бюджета. Это положение является одновременно фискальным принципом (принцип баланса) и бюджетным связыванием. На практике же это всего лишь «мягкое» бюджетное связывание, т. к. согласно тому же закону о ГБ местностям все еще разрешают мобилизовать внутренний капитал в случае, если 
есть необходимость вкладывать средства в строительство инфраструктуры даже при дисбалансе бюджета МОВ. Это положение является правовой основой для применения местными органами власти в целях финансирования инвестиционных потребностей местного социально-экономического развития, которые по сути являются финансированием дефицита местного бюджета. В действительности же в структуре долга более 30 \% заимствованы местностями у коммерческих банков и выпущены облигациями местных органов власти (например, в г. Хошимин), а 70 \% средств заимствованы у Вьетнамского банка развития (ВБР). Кредит в ВБР фактически представляет собой выпуск облигаций этого банка под гарантию Правительства СРВ.

В настоящее время качество кредитных портфелей МОВ никаким образом не оценивается. Более того, закон о ГБ также предусматривает, что бюджет МОВ состоит из своих доходов на 100 \%, излишек которых, если он имеется, направляется в ГБ. В случае дефицита средств правительство может выделять дополнительные субсидий из того же ГБ, если в этом есть необходимость.

Согласно описанию от Управления государственным долгом № 20 / 2017 / QH14, долг местных органов власти (МОВ) - это долг, подписанный, выпущенный или уполномоченный Народным комитетом провинций, городов иентрального подчинения. Соответственно, одним из факторов, оказывающих влияние на долг МOВ, является ОМОВ вид облигаџии сроком на один год или более, выпущенный или уполномоченньй Народным комитетом провинции для привлечения капитала в инвестиции в местные проекты и объекты» [5].

\section{Виды облигаций}

Существует два типа облигации местных органов власти. Первый тип - облигации с общими обязательствами (Gos-облигация) - это OMOB, гарантирующие как основную сумму, так и проценты со всеми финансовыми источниками и налоговыми полномочиями эмитента MOB. Это обеспечивает более высокое качество Gos-облигаций, чем облигации с конкретной или более ограниченной гарантией. Однако, как правило, реальный доход покупателей данного типа облигаций будет низким. Из-за высокой гарантийной собственности, основанной на платежеспособности местных органов власти, в США Gos-облигация, которую часто называют кредитно-доверительной облигацией, является наиболее популярным кредитно-денежным инструментом.

Второй тип - доходные облигации. Это те же ОМОВ, но с основной суммой и процентами, выплачиваемыми на основе дохода от полученного проекта, профинансированного этой же облигацией. Этот тип облигаций в основном ориентирован на развитие инфраструктуры, снижая нагрузку на ГБ. Доходные облигации обычно считаются менее качественными, чем Gos-облигации. Действительно, у них более привлекательная доходность, но являются более рискованными, т. к. не поддерживаются никаким другим источником, кроме индивидуального дохода от реализации инфраструктурных и иных проектов.

Большинству МОВ разрешено оставлять за собой все распределенные доходы в дополнение к своим доходам. Однако на сегодняшний день большинство провинциальных бюджетов имеют дефицит, несмотря на возможность полностью оставлять себе все доходы. В результате бюджет части провинций состоит на 50 \% из местных поступлений и $50 \%$ - из ГБ. Центральный бюджет же пополняют только около 10 МОВ.

Очевидно, что при таком механизме выделения средств из госбюджета МОВ не могут и не хотят получения самостоятельности в фискальных вопросах. По итогу вместо 
того, чтобы позволить местные заимствования для финансирования дефицита, трансфертные расходы возложили с местного бюджета на центральный. Более того, совокупность сверх доходов, которые МОВ перечислили в ГБ, могли бы снизить средний дефицит по стране в целом. Этот факт лишний раз демонстрирует хрупкие финансовые способности большинства МОВ.

Кроме того, чтобы создать предпосылки для экономического развития, создания новых рабочих мест и повышения доходов населения МОВ в первую очередь уделяют внимание проектам общественной инфраструктуры, медицинским, образовательным, общественным и транспортным объектам. Эти проекты строятся компаниями и подрядчиками под контролем МOB, поэтому для строительства этих объектов подрядчики должны привлекать капитал от коммерческих банков, а не за счет ГБ. Однако мрачный рынок недвижимости, медлительность в получении прибыли приводят к низкой окупаемости инфраструктурных проектов, а местные органы власти в итоге оказываются в затруднительном положении. Выпуск ОМОВ открыл бы для муниципалитетов и провинций новый канал повышения ликвидности и прозрачности инвестиций в инфраструктурные проекты. Кроме того, местные органы власти могут использовать инструменты облигаций для мобилизации неиспользуемого инвестиционного капитала населения. Таким образом, местные органы власти могут расплачиваться за «безнадежные долги» перед коммерческими банками, срок погашения которых приближается, в то же время продолжать вливать инвестиционный капитал в новые проекты. Предоставление населенным пунктам и регионам автономии для мобилизации инвестиционного капитала в целом и выпуска облигаций в частности на основе снижения зависимости от финансирования со стороны центрального бюджета имеет важное значение для обеспечения безопасности финансовых ресурсов, соблюдения политики в соответствии с текущими условиями социально-экономического развития Вьетнама.

\section{Решения о выпуске облигаций местных органов власти в целях обеспечения сохранности государственного долга Вьетнама}

Как было проанализировано ранее, для обеспечения национальной финансовой безопасности Правительство СРВ должно четко определить дефицит государственного бюджета и разработать дорожную карту по сокращению дефицита в среднесрочной перспективе. Кардинальная реализация дорожной карты по сокращению перерасхода государственного бюджета в ближайший период является одной из предпосылок для обеспечения объемов задолженности в пределах допустимых границ (дефицит государственного бюджета на уровне 2-4 \% ВВП). Соответственно, Правительство СРВ должно отдавать приоритет асинхронной реализации следующих решений:

1. Резко сократить гарантии правительства по внутренним и внешним займам для обеспечения стабильности непогашенных кредитов, обеспечить отношение государственного долга к ВВП на уровне, не превышающем разрешенный верхний предел долга. В то же время необходимо рассмотреть все программы и проекты, утвержденные компетентными органами, в отношении политики по правительственным гарантиям. Также надо ориентироваться в первую очередь на эффективные, срочные и гарантированные проекты для их дальнейшего представления в Национальное собрание или Постоянный комитет Национального собрания на рассмотрение и утверждение объемов предоставления гарантии правительства.

2. Надо разработать среднесрочный план государственных инвестиций с учетом сбалансированной и устойчивой налогово-бюджетной политики. В то же время требу- 
ется сузить инвестиционный капитал государства в направлении ключевых секторов экономики, имеющих важное социально-экономическое значение для провинций, населенных пунктов и страны в целом. Правительство не будет заимствовать средства сверх возможностей ГБ и сможет гарантировать, что пределы долга не будут нарушены. Правительство СРВ должно выделить кредиты по линии ОПР и льготных займов на среднесрочную перспективу, что позволит избежать лишних иностранных займов, которые ведут к увеличению государственного долга и потенциальному снижению кредитного рейтинга Вьетнама. Кроме того, надо ужесточить контроль кредитования - все займы надо оценивать в среднесрочной и долгосрочной перспективах, чтобы избежать их пагубного влияния на итоговые размеры госдолга. Надо отделить кредиты по линии ОПР и иностранные льготные кредиты в соответствии с графиком реализации программ и инвестиционных проектов в соответствии с обязательствами перед спонсорами.

3. Необходимо продолжить реструктуризацию государственного долга посредством мобилизации внутренних ресурсов для удовлетворения потребностей правительства в заемных средствах и снижения риска обменного курса с учетом получения способности постепенного уменьшения и прекращения поступления капитала по линии ОПР. Вместе с этим надо разработать механизм привлечения займов на рынке, чтобы создать ступеньку в преобразовании способа мобилизации займов по линиям ОПР и льготных займов. Для развития внутреннего рынка капитала необходимо создать механизм, позволяющий конвертировать договорные кредиты и займы из финансовых фондов в инвестиции в виде государственных облигаций и облигаций местных органов власти, чтобы повысить ликвидность и гибкость рынка. Кроме того, существует острая необходимость четко определить операции по привлечению капитала для инвестиций, компенсации дефицита государственного бюджета с управлением денежными средствами для обеспечения буферов ликвидности, что позволяет выпускать векселя, государственные облигации и облигации местных органов власти с разными сроками, целями управления и процентной ставкой. Для достижения этого необходимо развивать внутренний рынок капитала в направлении диверсификации долговых инструментов и привлечения иностранных инвесторов на рынки капитала и облигаций.

Наконец, важно уделять особое внимание развитию рынка облигаций местных органов власти, чтобы они стали каналом мобилизации капитала для социально-экономического развития, реализации инвестиционных проектов по расширению и развитию населенных пунктов, создания рабочих мест и увеличения доходов населения. Для стимулирования и создания условий выпуска облигаций МОВ Министерство финансов должно конкретизировать стандарты утверждения выпуска облигаций, чтобы облегчить местным властям содействие их выпуску для балансирования бюджетов, сокращения количества выдаваемых из центрального бюджета трансферов. Однако для реализации этого необходимо разработать научную дорожную карту, чтобы избежать возникновения движения, когда выпускаются облигации местных органов власти.

При утверждении механизма выпуска облигаций Министерству финансов следует разработать план постепенного перехода от метода выпуска на основе способности организации, выпускающей облигации, к раскрытию информации (внесение поправок в указы и публикация руководящих циркуляров и стандартов, разрешающих выпуск облигаций) для любых текущих финансовых условий. Наряду с этим, местные органы власти должны сделать информацию о размерах местного бюджета максимально публичной и прозрачной с ее дальнейшей публикацией в СМИ, что потенциальные инвесторы могли легко оценить способности МОВ выплатить долг. Соответственно, эффективность использования капитала каждого населенного пункта будет повышена. 
Правильное и эффективное использование привлеченного капитала увеличит доверие людей к местным органам власти, повысит национальную финансовую безопасность провинций и городов. Это приведет к более легкому выпуску облигаций местных органов власти, высокой приемлемости и меньшим затратам на мобилизацию по мере увеличения индекса уверенности. В то же время облигации местных органов власти станут эффективным инструментом, помогающим государству в обеспечении национальной финансовой безопасности, движущей силой для эффективных вложений средств и активной реализации стратегии устойчивого экономического роста в соответствии с сильными сторонами и приоритетами каждого населенного пункта.

Исследование выполнено при финансовой поддержке РФФИ и ВАОН № 21-510-92007.

\section{СПИСОК ЛИТЕРАТУРЫ}

1. Minh Khôi. Khống chế hạn mức bội chi và nợ của chính quyền địa phương. URL: https://tapchitaichinh.vn/su-kien-noi-bat/khong-che-han-muc-boi-chi-va-no-cua-chinh-quyen-diaphuong-326492.html (дата обращения 01.03.2021).

2. Bạch Huệ. Tỷ lệ nợ công/GDP của Việt Nam không ngừng giảm. URL: https://vneconomy.vn/ty-le-nocong-gdp-cua-viet-nam-khong-ngung-giam-20201022093041725.htm (дата обращения 01.03.2021).

3. Бюллетень государственного долга № 6,9/2017 // Департамент управления долгом и внешних финансов Министерства финансов. URL: https://www.mof.gov.vn/webcenter/portal/btc/r/lvtc/qln/ qln_chitiet?dDocName=MOFUCM145309\&_afrLoop=87074500517855\#\%40\%3F_afrLoop\%3D87074 500517855\%26dDocName\%3DMOFUCM145309\%26_adf.ctrl-state\%3D1cjc3up7ij_79 (дата обращения 28.02.2021).

4. Бач Хюэ. Отношение государственного долга к ВВП Вьетнама постоянно уменьшается. URL: https://vneconomy.vn/ty-le-no-cong-gdp-cua-viet-nam-khong-ngung-giam-20201022093041725.htm (дата обращения 28.02.2021).

5. Luật quản lý nợ công № 20/2017/QH14. URL: https://thuvienphapluat.vn/van-ban/Tai-chinh-nhanuoc/Luat-Quan-ly-no-cong-337165.aspx (дата обращения 01.03.2021).

Поступила 02.03.2021 г. 
UDC 336.763.33:342.553(597)

\title{
ISSUE OF LOCAL GOVERNMENT BONDS - DECISION TO IMPLEMENT THE STRATEGY OF PUBLIC DEBT OF VIETNAM
}

\author{
Dao Thanh Binh, \\ binh.daothanh@hust.edu.vn
}

Hanoi University of Science and Technology,

1, Dai Co Viet street, Hanoi, 11615, Vietnam

Dao Thanh Binh, PhD, head of the Financial Management Department.

\begin{abstract}
Despite the difficult international situation, exacerbated by geopolitical tensions in the world in general and the COVID-19 pandemic, the Vietnamese economy is gradually recovering, but certain difficulties and problems still remain. In recent years, thanks to the active work of the Government of the Socialist Republic of Vietnam, timely decisions of the Ministry of Finance, other relevant departments and institutions, as well as local authorities, the goals of the Public Debt Strategy have been gradually implemented, corresponding to the implementation of the tasks of socio-economic development, poverty reduction and building the necessary infrastructure asynchronously. By 2020, the indicators of the national debt of the Socialist Republic of Vietnam are mainly within acceptable limits, but from the point of view of obligations to repay debt in the near future, potential risks still remain. This article is devoted to assessing the results of the implementation of Vietnam Public Debt Strategy for 2011-2020 for providing appropriate recommendations for ensuring national financial security, as well as mobilizing resources of local government bonds for effective and sustainable economic growth and development.
\end{abstract}

Key words: Government budget, government debt, Vietnam Government Debt Strategy, local government bonds.

The research was financially supported by the RFBR and VASS no. 21-510-92007.

\section{REFERENCES}

1. Min Hoi. Khống chế hạn mức bội chi và nợ của chính quyền địa phương [Limit overspending and local government debt]. Available at: https://tapchitaichinh.vn/su-kien-noi-bat/khong-che-han-muc-boi-chiva-no-cua-chinh-quyen-dia-phuong-326492.html (accessed 1 March 2021).

2. Bach Hue. Tỷ lệ nợ công/GDP của Việt Nam không ngùng giảm [Vietnam's public debt/GDP ratio keeps decreasing]. Available at: https://vneconomy.vn/ty-le-no-cong-gdp-cua-viet-nam-khong-ngung-giam20201022093041725.htm (accessed 1 March 2021).

3. Byulleten gosudarstvennogo dolga no. 6,9/2017 [Public Debt Bulletin No. 6.9 / 2017]. Departament upravleniya dolgom $i$ vneshnikh finansov Ministerstva finansov. Available at: https://www.mof.gov.vn/webcenter/portal/btc/r/lvtc/qln/qln_chi-

tiet?dDocName=MOFUCM145309\&_afrLoop=87074500517855\#\%40\%3F_afrLoop\%3D870745 00517855\%26dDocName\%3DMOFUCM145309\%26_adf.ctrl-state\%3D1cjc3up7ij_79 (accessed 28 February 2021).

4. Bach Khyue. Otnoshenie gosudarstvennogo dolga $k$ VVP Vetnama postoyanno umenshaetsya [Vietnam's public debt to GDP ratio is steadily declining]. Available at: https://vneconomy.vn/ty-le-no-cong-gdp-cuaviet-nam-khong-ngung-giam-20201022093041725.htm (accessed 28 February 2021).

5. Luật quản lý nợ công № 20/2017/QH14 [Law on Public Debt Management № 20/2017/QH14]. Available at: https://thuvienphapluat.vn/van-ban/Tai-chinh-nha-nuoc/Luat-Quan-ly-no-cong-337165.aspx （accessed 1 March 2021).

Received: 2 March 2021. 